\title{
Lesiones orales asociadas con la enfermedad del virus de inmunodeficiencia humana en pacientes adultos, una perspectiva clínica
}

\author{
Francisca Donoso-Hofer
}

\section{Oral lesions associated with human immunodeficiency virus disease in adult patients, a clinical perspective}

Among the clinical manifestations which may occur in HIV/AIDS patients, oral lesions are relevant because there are easily accessible and usually the diagnosis is made through clinical features. Some oral manifestations are strongly related with HIV/AIDS patients indicating infection and progression to AIDS and also allow monitoring the success or failure of using antiretroviral therapy. The massive introduction of antiretroviral therapy has changed the morbidity and mortality, frequency, type of clinical manifestation and the timing of the classic opportunistic complications. The aim of this review is to provide an updated of the classical clinical features of the most frequent and relevant HIV/AIDS oral manifestations, considering the fundamental clinical features for their diagnosis.

Key words: Human immunodeficiency virus, acquired immunodeficiency syndrome, oral manifestations, diagnosis.

Palabras clave: Virus de inmunodeficiencia humana, síndrome de inmunodeficiencia adquirida, manifestaciones orales, diagnóstico.

\section{Introducción}

$\mathrm{E}$ $\mathrm{n}$ condiciones de normalidad, el epitelio de la mucosa oral juega un rol importante en la protección del hospedero contra los agentes patógenos que provocan infecciones. Sin embargo, en pacientes con infección por VIH/SIDA, el epitelio oral experimenta alteraciones moleculares que aumentan la susceptibilidad a contraer infecciones. A pesar de lo efectiva que resulta la terapia anti-retroviral (TARV) aumentando el recuento de linfocitos T CD4, no logra conseguir una completa recuperación inmune de las células del epitelio de la mucosa oral, persistiendo un grado de susceptibilidad frente a los agentes infecciosos e incluso generando un grado de vulnerabilidad frente a los efectos tóxicos de los fármacos anti-retrovirales ${ }^{1}$.

Dentro de las manifestaciones que pueden aparecer en los pacientes con infección por VIH/SIDA, las lesiones de la cavidad oral son de gran relevancia. Estudios realizados alrededor del mundo indican que estas lesiones pueden estar presentes en hasta $50 \%$ de las personas con infección por VIH y en $80 \%$ de las personas con un diagnóstico de SIDA $^{2}$. Las diferencias en porcentaje se deben a la variedad de investigaciones, metodologías, tipos de estudio, heterogeneidad epidemiológica, región demográfica y tipo de terapia que esté recibiendo el paciente ${ }^{1}$. A la fecha, en nuestro país, no existen publicaciones actualizadas en revistas indexadas que refieran la frecuencia de manifestaciones orales en pacientes infectados por VIH/SIDA, así como tampoco revisiones en torno a las características clínicas y métodos diagnósticos de las manifestaciones orales de estos pacientes.

La introducción masiva de la TARV, no sólo ha reducido la morbi-mortalidad de las clásicas complicaciones oportunistas sino que se ha modificado su frecuencia, el tipo de manifestaciones clínicas y momento de aparición ${ }^{3}$. Es importante entender que las lesiones orales provocadas por agentes oportunistas ocurren en pacientes con infección por VIH/SIDA, estén o no bajo TARV. Si bien, la ocurrencia de algunas lesiones clásicamente asociadas a infección por VIH como el sarcoma de Kaposi, leucoplasia pilosa, enfermedad periodontal y ulceraciones de la mucosa, han disminuido con la introducción de TARV, otras condiciones como la candidiasis oro-faríngea, se han mantenido constantes, mientras que las lesiones papilomatosas y la patología de glándulas salivales han aumentado ${ }^{1}$.

La presencia de las lesiones orales continúa siendo significativa ya que podría ser indicativa de un deterioro del sistema inmunológico del paciente, considerándoseles como marcadores tempranos de la enfermedad. También pueden asociarse a una disminución del recuento de linfocitos T CD4 y aumento en la carga viral ${ }^{4-6}$.

En el contexto de un paciente con infección por VIH/
Universidad de Chile Facultad de Odontología. Departamento de Cirugía y Traumatología Máxilo-facial

La autora de este trabajo declara no tener conflictos de interés

Recibido: 15 de junio de 2015 Aceptado: 2 de diciembre de 2015

Correspondencia a:

Francisca Donoso Hofer frandonoso@u.uchile.cl 
SIDA, la importancia de las lesiones orales radica principalmente en que:

- Son fácilmente accesibles y por lo general su diagnóstico se efectúa a través de signos clínicos.

- Algunas manifestaciones orales están fuertemente relacionadas con el VIH/SIDA por lo que indican sospecha de infección.

- Pueden indicar progresión a etapa SIDA y

- Permiten monitorizar el éxito o fracaso de la TARV empleada ${ }^{2}$.

Las manifestaciones orales pueden estar presentes en todas las etapas de la infección por VIH y, debe ser enfatizado el hecho de que no existe una lesión oral que se presente de manera patognomónica en pacientes infectados por VIH/SIDA ${ }^{7}$. De igual forma, es importante mencionar que es posible encontrar muchas de estas condiciones en pacientes en que la inmunosupresión tiene otro origen o incluso, en pacientes inmunocompetentes.

En la década de los ochenta, se propuso una clasificación de las manifestaciones orales asociadas a la infección por VIH/SIDA en pacientes adultos basándose en el grado de asociación o frecuencia de dichas condiciones patológicas con la presencia del virus ${ }^{8}$. Si bien esta clasificación surge de una colaboración entre un grupo de expertos en el tema, sigue teniendo vigencia y considera tres grupos que se mencionan a continuación y que se presentan en la Tabla 1.

- Lesiones fuertemente asociadas a infección por VIH.

- Lesión menos comúnmente asociadas a infección por VIH.

- Lesiones vistas en infección por VIH.

En el año 2009, esta clasificación fue revisada y actualizada por expertos agrupados en OHARA (Oral HIV/AIDS Research Alliance $)^{9}$ con el objetivo de facilitar el diagnóstico de estas lesiones para realizar estudios clínicos y epidemiológicos. Además de los descriptores clínicos, se agregaron síntomas reportados por los pacientes y tiempo de duración de las lesiones.

El objetivo de esta revisión es presentar una actualización de aquellas manifestaciones orales asociadas al VIH/SIDA que son más frecuentes y que tienen mayor relevancia clínica, considerando las características fundamentales para su diagnóstico. El resumen de las lesiones se presenta en la Tabla 2.

\section{Candidiasis oral}

Es la infección oportunista de mayor prevalencia en los pacientes infectados por VIH/SIDA, considerando todos los rangos etarios, género y razas; su variante pseudomembranosa es la más diagnosticada ${ }^{1}$. Es causada por el género fúngico llamado Candida spp, que constituye parte de la microbiota que coloniza la cavidad oral. Candida albicans es la especie que más comúnmente se aísla. No obstante, se han recuperado otras especies en pacientes infectados por VIH como Candida glabrata, Candida tropicalis, Candida krusei, Candida parapsilosis, Candida guilliermondii o Candida dubliniensis, especialmente en aquellos pacientes refractarios a los tratamientos con azoles ${ }^{1}$.

Cuando la candidiasis se presenta en la cavidad oral, ocasiona incomodidad, dolor y pérdida del gusto, afectando la calidad de vida. Su aparición, particularmente en adultos jóvenes sin condiciones predisponentes como diabetes mellitus, desnutrición, xerostomía, prótesis dentales acrílicas removibles o tratamiento con antimicrobianos, corticosteroides u otros agentes inmunosupresores, podría ser sugerente de infección por VIH y se ha utilizado también como marcador de su gravedad ${ }^{10}$. En etapas tempranas de la infección por VIH, la candidiasis afecta principalmente a la mucosa oral. Sin embargo, en etapas

Tabla 1. Clasificación de lesiones orales en pacientes adultos con infección por VIH/SIDA

Grupo 1. Lesiones fuertemente asociadas a infección por VIH

Candidiasis:

eritematosa

pseudomembranosa

Leucoplasia pilosa

Sarcoma de Kaposi

Linfoma no Hodgkin

Enfermedad periodontal:

eritema gingival lineal

periodontitis y gingivitis

úlcero-necrosante
Grupo 2. Lesiones menos comúnmente asociadas Grupo 3. Lesiones vistas en infección por VIH a infección por VIH

Infecciones bacterianas atípicas

Pigmentaciones melánicas

Patología de glándula salival:

xerostomía

aumento de volumen

Infecciones virales:

virus de papiloma humano

virus herpes simplex

virus varicela-zoster

Ulceraciones inespecíficas
Enfermedad por arañazo de gato

Reacciones a medicamentos

Infecciones por hongos distintos a Candida spp

Infecciones virales por CMV

Alteraciones neurológicas: neuralgia del trigémino

Adaptada desde EEC Clearinghouse ${ }^{8}$ de acuerdo a lesiones más frecuentes en nuestro medio. 


\begin{tabular}{|c|c|c|c|c|c|c|}
\hline Manifestación oral & Etiología & Color & Carácter & Localización & Síntomas & Diagnóstico \\
\hline $\begin{array}{l}\text { Candidiasis } \\
\text { pseudomembranosa }\end{array}$ & Hongo tipo Candida sp & $\begin{array}{l}\text { Blanco } \\
\text { Amarillo }\end{array}$ & $\begin{array}{l}\text { Placas que no se } \\
\text { desprenden al raspado }\end{array}$ & En todos lados & $\begin{array}{l}\text { Asintomáticos o sensación } \\
\text { urente }\end{array}$ & Clínico principalmente \\
\hline $\begin{array}{l}\text { Candidiasis } \\
\text { eritematosa }\end{array}$ & Hongo tipo Candida sp & Rojo & Máculas o placas & $\begin{array}{l}\text { Paladar, dorso lengua, } \\
\text { mucosa bucal }\end{array}$ & $\begin{array}{l}\text { Asintomáticos o sensación } \\
\text { urente }\end{array}$ & Clínico principalmente \\
\hline $\begin{array}{l}\text { Gingivitis/periodontitis } \\
\text { úlcero-necrosantes }\end{array}$ & Bacterias periodontales & $\begin{array}{l}\text { Rojo } \\
\text { Blanco }\end{array}$ & Necrótico, olor fétido & $\begin{array}{l}\text { Tejido periodontal y } \\
\text { hueso alveolar }\end{array}$ & $\begin{array}{l}\text { Dolor, movilidad de piezas } \\
\text { dentarias }\end{array}$ & Clínico y radiográfico \\
\hline Leucoplasia pilosa & Virus de Epstein-Barr & Blanco & Corrugado o vertical & $\begin{array}{l}\text { Bordes laterales de } \\
\text { lengua }\end{array}$ & Asintomáticos & Clínico principalmente \\
\hline Herpes labial simple & $\begin{array}{l}\text { Virus herpes simplex } \\
1 \text { y } 2\end{array}$ & $\begin{array}{l}\text { Rojo } \\
\text { Mucosa }\end{array}$ & $\begin{array}{l}\text { Vesículas, úlceras o } \\
\text { costras }\end{array}$ & $\begin{array}{l}\text { Bermellón labio, } \\
\text { encía, paladar duro }\end{array}$ & $\begin{array}{l}\text { Sensación urente } \\
\text { Dolor }\end{array}$ & Clínico principalmente \\
\hline $\begin{array}{l}\text { Papiloma, condiloma, } \\
\text { verruga oral }\end{array}$ & Virus papiloma humano & $\begin{array}{l}\text { Blanco } \\
\text { Mucosa }\end{array}$ & $\begin{array}{l}\text { Digitiforme } \\
\text { Solevantado }\end{array}$ & En todos lados & $\begin{array}{l}\text { Asintomático o dificultad } \\
\text { en masticación por tamaño }\end{array}$ & $\begin{array}{l}\text { Biopsia } \\
\text { Tipificación RPC }\end{array}$ \\
\hline Sarcoma de Kaposi & $\begin{array}{l}\text { Virus herpes humano } \\
\text { tipo } 8\end{array}$ & $\begin{array}{l}\text { Rojo } \\
\text { Rojo vinoso } \\
\text { Morado }\end{array}$ & $\begin{array}{l}\text { Plano } \\
\text { Mácula } \\
\text { Nódulo } \\
\text { Solevantado }\end{array}$ & $\begin{array}{l}\text { Cualquier lado con } \\
\text { predilección por } \\
\text { paladar y encías }\end{array}$ & $\begin{array}{l}\text { Asintomáticos } \\
\text { Doloroso cuando se ulcera } \\
\text { o invade estructuras }\end{array}$ & Biopsia \\
\hline Linfoma no Hodgkin & Etiología multifactorial & $\begin{array}{l}\text { Rojo } \\
\text { Blanco } \\
\text { Necrótico }\end{array}$ & $\begin{array}{l}\text { Solevantado } \\
\text { Ulcerado } \\
\text { Nodular } \\
\text { Indurado }\end{array}$ & $\begin{array}{l}\text { Cualquier lado con } \\
\text { predilección por el } \\
\text { paladar, encías y } \\
\text { orofaringe }\end{array}$ & $\begin{array}{l}\text { Dolor cuando invade } \\
\text { estructuras o cuando se } \\
\text { úlcera }\end{array}$ & $\begin{array}{l}\text { Biopsia y estudios in- } \\
\text { muno-histoquímicos }\end{array}$ \\
\hline Úlceras inespecíficas & Idiopáticas & $\begin{array}{l}\text { Blancas } \\
\text { Amarillas } \\
\text { Rojas }\end{array}$ & Úlceras & $\begin{array}{l}\text { Mucosa labio, lengua, } \\
\text { piso de boca, paladar } \\
\text { blanco }\end{array}$ & $\begin{array}{l}\text { Dolorosas } \\
\text { Sensación urente }\end{array}$ & Principalmente clínico \\
\hline
\end{tabular}

más avanzadas, puede progresar a la mucosa esofágica causando una candidiasis esofágica invasora, que es categorizada como una patología definitoria de SIDA. Las presentaciones orales más frecuentes de candidiasis son la pseudomembranosa, eritematosa y queilitis angular ${ }^{11}$.

\section{Candidiasis pseudomembranosa}

Es la forma más clásica de presentación. Se caracteriza por la presencia de grumos o placas blanco amarillentas, de consistencia blanda o gelatinosa, que crecen de manera centrífuga. Al ser raspadas se desprenden fácilmente dejando una zona eritematosa, erosionada o ulcerada, en ocasiones dolorosa, con una mucosa adyacente normal en apariencia ${ }^{9,12}$ (Figura 1).

Las lesiones se pueden localizar en la mucosa bucal, lengua, cara interna de la mejilla y en el paladar duro y blando ${ }^{10,11}$.

Los pacientes pueden presentarse asintomáticos o en algunos casos referir una sensación urente.

El diagnóstico usualmente se basa en los hallazgos clínicos, siendo más sencillo de realizar cuando las lesiones se encuentran en la cara interna de las mejillas, labios o paladar, ya sea duro o blando. Cuando las lesiones se localizan en el dorso lingual, muchas veces puede confundirse con saburra o restos de alimentos, sobre todo en pacientes con una higiene oral deficiente. También puede darse en pacientes con infección por VIH/SIDA que sean portadores de prótesis dentales, donde las prótesis acrílicas

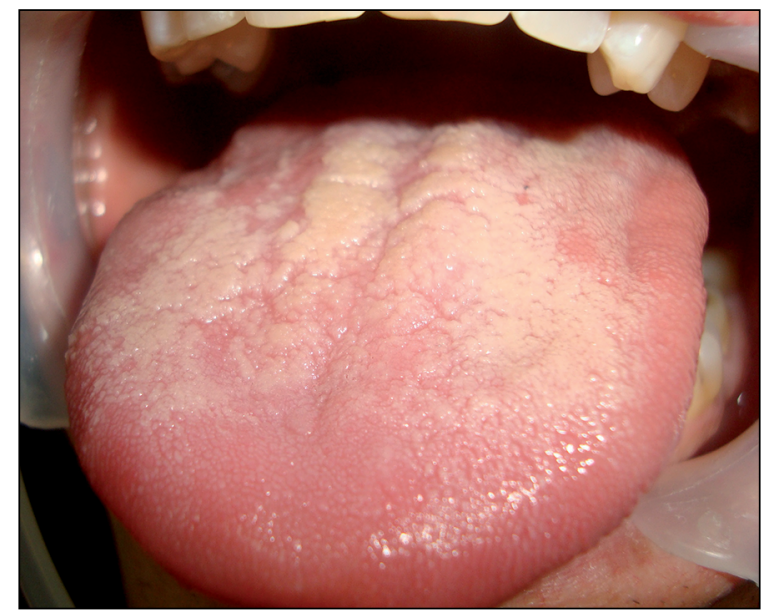

Figura 1. Candidiasis pseudomembranosa en el dorso lingual. Se observa una capa blanca que no se desprende al raspado (Hospital San Juan de Dios). 
son colonizadas por Candida spp, con mayor frecuencia. Por lo general, cuando la candidiasis es sub-protésica suele presentarse como eritematosa.

Cuando se ha efectuado un diagnóstico en base a los hallazgos clínicos y la terapia antimicótica empírica no da los resultados esperados, es recomendable realizar un diagnóstico más acucioso a través de cultivo y antifungigrama e incluso, biopsia.

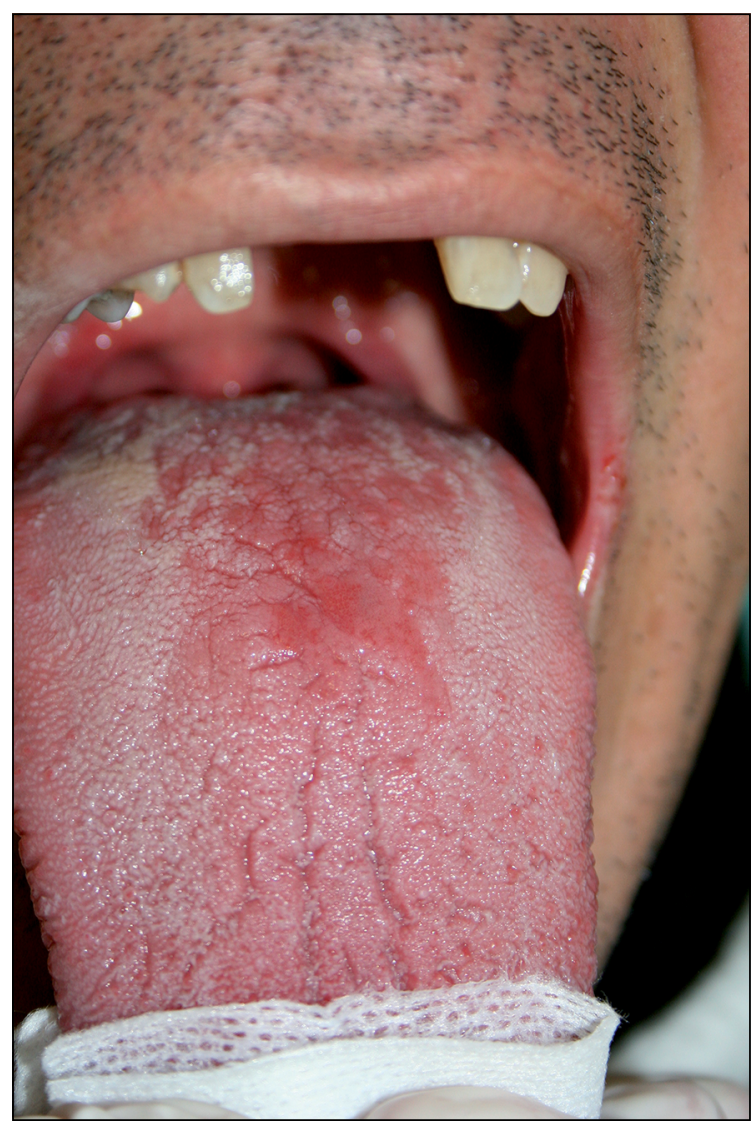

Figura 2. Candidiasis eritematosa dorso lingual. Muchas veces puede darse de manera simultánea con candidiasis pseudomembranosa (Hospital San Juan de Dios).

Figura 3. Queilitis angular bilateral. Se observan las comisuras resecas y quebradizas. (Hospital San Juan de Dios).

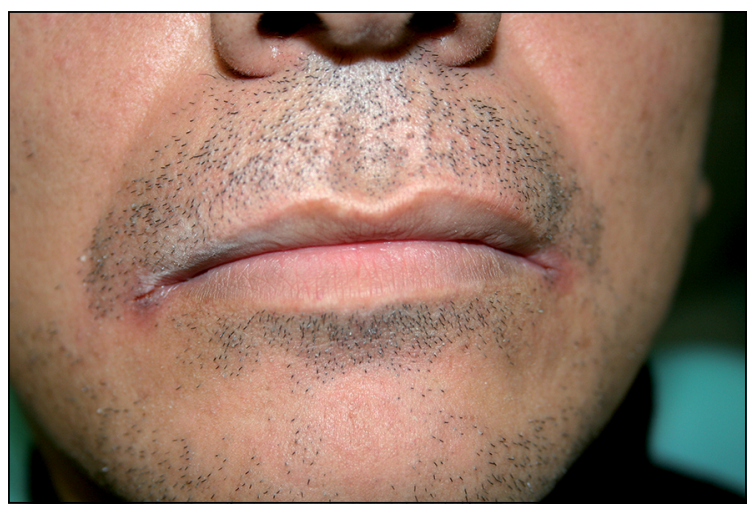

\section{Candidiasis eritematosa o atrófica}

Se presenta como una lesión sutil, de color rojo, por lo general plana, ubicada principalmente en la cara dorsal de una lengua que se presenta depapilada o en el paladar duro. Puede darse en combinación con la modalidad pseudomembranosa (Figura 2). Generalmente es sintomática: El paciente acusa sensación urente al consumir alimentos salados o ácidos ${ }^{11}$.

Al igual que en la candidiasis pseudomembranosa, el diagnóstico se basa en los hallazgos clínicos. En casos de estomatitis sub-protésica o candidiasis eritematosa en pacientes portadores de prótesis, debe determinarse si la aparición de esta condición es producto de la colonización excesiva de hongos en el aparato protésico u obedece a la inmunosupresión del enfermo. Si la zona eritematosa está en estrecha relación con las zonas de apoyo de la prótesis en la mucosa, es probable que sea una estomatitis sub-protésica. En caso de no remitir frente a medidas locales de higiene o uso de anti fúngicos empíricos, se recomienda la toma de cultivo y eventual biopsia para hacer diagnóstico diferencial, por ejemplo, con un liquen plano atrófico erosivo o una eritroplasia.

Existe otra entidad clínica que por lo general es causada por Candida spp, que se denomina queilitis angular; sin embargo, al no ser este tipo de hongo el único agente etiológico, algunos autores la consideran como una lesión asociada $^{12}$. Se caracteriza por un enrojecimiento intenso de las comisuras labiales (habitualmente bilateral), con aparición de grietas o fisuras y formación de costras (Figura 3). Esta condición no es exclusiva de pacientes con inmunosupresión ya que puede asociarse al envejecimiento, a la disminución de la dimensión vertical, hiposialia, déficits vitamínicos y de hierro, diabetes mellitus, etc.

Puede ocurrir o no en concomitancia con candidiasis pseudomembranosa o eritematosa y puede persistir por un largo período de tiempo si no es tratada ${ }^{11}$. Los pacientes pueden estar asintomáticos o referir molestias al realizar una apertura excesiva de la boca.

\section{Leucoplasia pilosa}

Es una infección oportunista producida por la reactivación desde el estado latente del virus de Epstein-Barr (VEB). Frecuentemente es detectada en pacientes infectados por VIH, pero también en aquellos que presentan cuadros de inmunodepresión por otras causas.

Es una lesión hiperplásica benigna, de color blanquecino, que no se desprende al raspado y que se ubica usualmente en los bordes laterales de la lengua, de forma bilateral o unilateral, aunque también puede encontrarse en sus superficies dorsal y ventral. Se describe con un patrón hiperplásico vertical o corrugado (Figura 4). Normalmente se presenta de forma asintomática, no tiene un potencial maligno y no requiere terapia, a menos que 


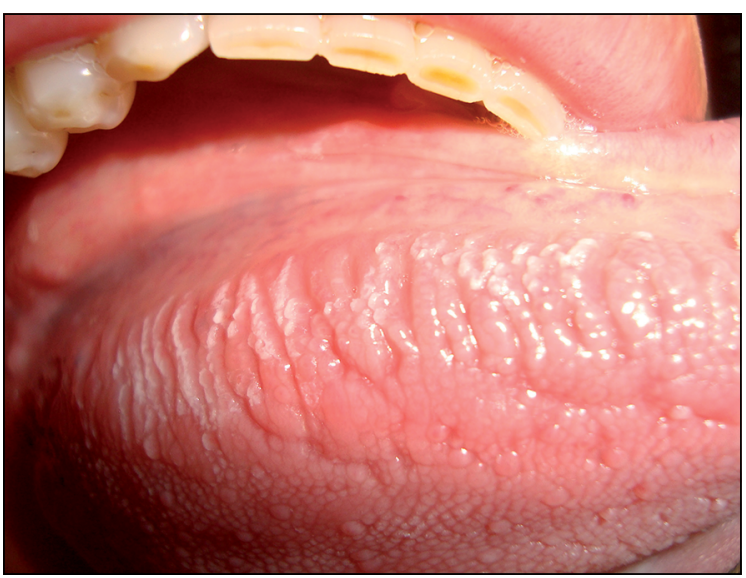

Figura 4. Leucoplasia pilosa en borde lateral de la lengua. Se observa una disposición vertical de la lesión (Hospital San Juan de Dios).

existan alteraciones cosméticas relevantes, ya que, por lo general, remite espontáneamente ${ }^{8,11}$.

Si bien es una lesión bastante frecuente en los reportes de la literatura internacional, muchas veces es sub-diagnosticada por no realizar un adecuado examen de los bordes laterales de la lengua. Su diagnóstico es esencialmente clínico; sin embargo, frente a la ausencia de un tratamiento empírico efectivo podría pensarse en una leucoplasia, siendo necesario, para realizar el diagnóstico diferencial, efectuar una biopsia y estudio histopatológico. La detección de VEB a través de reacción de polimerasa en cadena (RPC) desde una muestra obtenida de la lesión podría evitar el procedimiento quirúrgico. La presencia de VEB desde sangre periférica no siempre es positiva a pesar de estar en presencia de leucoplasia pilosa.

\section{Sarcoma de Kaposi}

Corresponde a una neoplasia maligna asociada al virus herpes humano tipo 8 (VHH-8). Es una enfermedad angioproliferativa, multicéntrica, de origen endotelial, con una patogenia y una expresión clínica bastante heterogénea y un tipo de crecimiento que está directamente relacionado con la respuesta inmune del hospedero ${ }^{1}$. Comienza como una reacción anti-inflamatoria hiperplásica reactiva y un proceso angiogénico que evoluciona a un sarcoma ${ }^{11}$. La apariencia clínica puede variar dependiendo del tiempo de duración de la lesión. Inicialmente, las lesiones tienden a ser planas y asintomáticas, donde el color transita desde el rojo hasta llegar al morado ${ }^{1,11}$. Si bien pueden asemejarse a una equimosis, la vitropresión es negativa. También pueden presentarse como aumentos de volumen irregulares, de color rojo vinoso, que cuando alcanzan un tamaño considerable pueden provocar deformidad facial y alteraciones en la masticación, deglución y

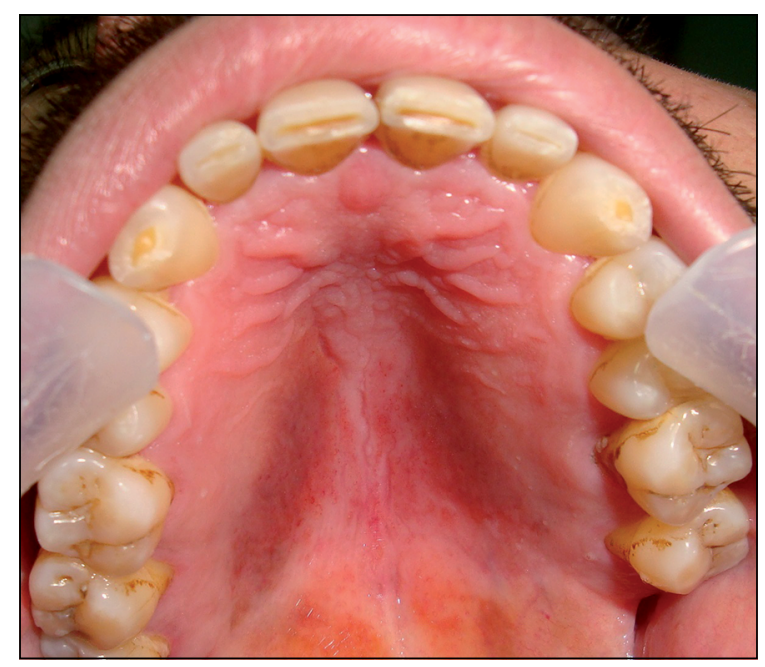

Figura 5. Sarcoma de Kaposi palatino en forma de mácula Color rojo vinoso (Hospital San Juan de Dios).

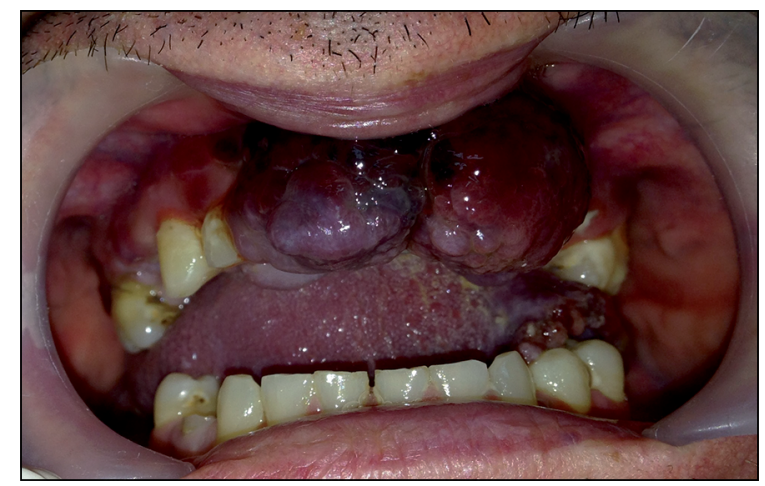

Figura 6. Gran sarcoma de Kaposi localizado en el maxilar superior y borde lateral de la lengua que interfiere con la masticación y la fono articulación (Hospital San Juan de Dios).

fono-articulación. Pueden ulcerarse producto de trauma masticatorio, ser dolorosas e incluso, pueden sangrar frente a estímulos (Figuras 5 y 6).

Con mayor frecuencia se localiza en el paladar, encía y dorso lingual y es reconocido como una neoplasia definitoria de SIDA en individuos infectados por $\mathrm{VIH}^{1,9}$.

Es aún la neoplasia maligna más frecuente en los pacientes con infección por VIH/SIDA, aunque su incidencia ha disminuido dramáticamente desde la introducción de TARV. El sarcoma de Kaposi oral o cráneo-facial ocurre en 40 a $60 \%$ de los pacientes con SIDA y es la primera presentación de inmunosupresión por VIH en un quinto de los pacientes que lo presentan ${ }^{1,13}$.

Si bien, en la gran mayoría de los casos, las lesiones son clínicamente características, el diagnóstico definitivo está dado por la biopsia y su posterior estudio histopatológico, lo que resulta esencial si el tratamiento de la lesión va a realizarse en base a quimioterapia ${ }^{13}$.

En relación al estudio por imágenes, cuando las lesiones son de tamaño considerable y se localizan en el paladar 
o encía puede observarse una reabsorción del hueso alveolar que puede evidenciarse en radiografías panorámicas o retro-alveolares. En caso de grandes lesiones, que se presentan como masas que invaden otros tejidos, pueden estudiarse a través de TAC (tomografía axial computada) con contraste o RM (resonancia magnética) ${ }^{1}$.

\section{Linfoma no Hodgkin}

El linfoma no Hodgkin (LNH) corresponde a la segunda neoplasia maligna en frecuencia en pacientes con enfermedad por VIH/SIDA, luego del sarcoma de Kaposi. Pertenece a un grupo heterogéneo de desórdenes linfoproliferativos de células B, T o natural killer (NK) y es reconocido como una neoplasia definitoria de SIDA en individuos con infección por VIH. Por lo general, debuta

Figura 7. Linfoma no Hodgkin en el hemi-maxilar izquierdo (Hospital San Juan de Dios).

Figura 8. Enfermedad periodontal agresiva en paciente con infección por VIH/SIDA. Se observa pérdida de inserción de los dientes mandibulares anteriores (Hospital San Juan de Dios).

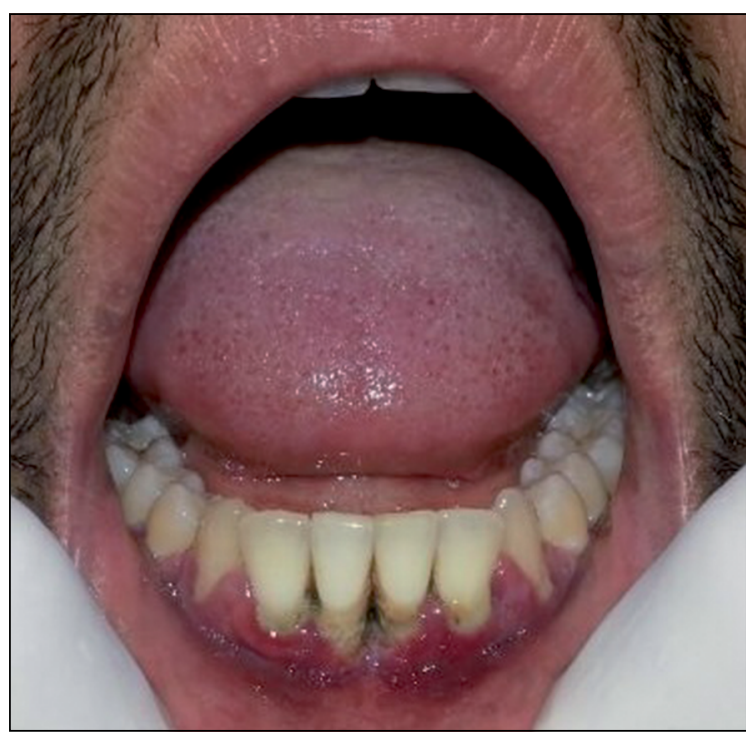

a nivel de los linfonodos, y cuando lo hace al margen de estos tejidos, el sitio donde con mayor frecuencia se encuentra es el tracto gastrointestinal. El tipo más común y agresivo que proviene de las células de estirpe B es el linfoma de Burkitt ${ }^{1}$.

El linfoma no Hodgkin se presenta como masas de tejido blando, con o sin ulceraciones y necrosis tisular, que usualmente involucra la mucosa gingival, palatina y alveolar y la región de las amígdalas tonsilares. Cuando se presenta como una tumoración, sus bordes son elevados, abollonados, anfractuosos y firmes (Figura 7). En las encías, puede asemejarse a la enfermedad periodontal, causando engrosamiento de la mucosa, formación de masas y ulceraciones. Puede cursar con dolor en etapas más tardías, sobre todo cuando la lesión invade estructuras neurológicas.

Para realizar el diagnóstico y su etapificación, es mandatoria la realización de una biopsia y estudio histopatológico, complementado con técnicas de inmunohistoquímica y biología molecular.

Cuando se localiza en la mucosa gingival en forma de grandes masas, existen cambios radiográficos como ensanchamiento en la línea periodontal y pérdida de la cortical alveolar lo que se puede evidenciar en las radiografías retro alveolares o panorámicas ${ }^{1}$. Se recomienda el estudio con TAC con medio de contraste para evaluar su extensión.

\section{Enfermedad periodontal}

Las lesiones periodontales asociadas a la infección por VIH incluyen el eritema gingival lineal y las enfermedades periodontales necrosantes que pueden sub-clasificarse en gingivitis úlcero-necrosante y periodontitis úlceronecrosante, las que se consideran distintos estadíos de la misma enfermedad ${ }^{14}$.

\section{Gingivitis úlcero-necrosante (GUN) y periodontitis úlcero-necrosante (PUN)}

Tanto GUN como PUN forman parte del mismo proceso de enfermedad; sin embargo, se diferencian por el tipo de tejido involucrado, GUN cursa con destrucción y necrosis del tejido gingival y PUN con destrucción del tejido periodontal de inserción que clínicamente se expresa con movilidad de los dientes. En ambas entidades existe una rápida destrucción de tejido blando y duro, respectivamente. Ambas entidades se caracterizan por presentar dolor intenso, hemorragia y olor fétido. Su evolución es aguda y rápidamente progresiva, llegando a causar exposición ósea e incluso pérdida de dientes cuando existe una importante destrucción de las estructuras periodontales ${ }^{11}$ (Figura 8).

En su etiología están implicados numerosos microorganismos pertenecientes a la microbiota anaeróbica. Además, en su etio-patogenia participan otros factores 
como la higiene oral, el estado periodontal previo, el tabaquismo, etc. ${ }^{12}$. Pacientes diabéticos de larga data, mal controlados metabólicamente también pueden presentar estos tipos de enfermedad periodontal agresiva, razón por la cual no puede atribuirse exclusivamente a pacientes inmunosuprimidos por la infección con VIH/SIDA.

El diagnóstico está basado en las características clínicas en asociación con la medición de recesión gingival, pérdida de inserción, tipo de reabsorción ósea y movilidad de las piezas dentarias.

\section{Eritema gingival lineal}

Como su nombre lo indica, se caracteriza por una banda de color rojo que se localiza en la encía marginal, sin presentar ulceración, pérdida de inserción ósea o propensión al sangrado. Ocasionalmente puede extenderse más allá de la unión muco-gingival ${ }^{1}$. El color eritematoso de la lesión no se condice con la cantidad de placa bacteriana presente en la región e incluso persiste luego de remover la placa bacteriana y mejorar la higiene local. Si bien su etiología y patogenia es desconocida, se piensa que podría ser una lesión bacteriana/fúngica. La microbiota sub-gingival presente en los pacientes infectados por VIH/ SIDA, presenta microorganismos patógenos periodontales clásicos y una gran prevalencia de patógenos oportunistas. Se postula que esta condición podría exacerbarse por la presencia de Candida spp y virus similares al virus herpes simplex (VHS) y por una respuesta inflamatoria exacerbada mediada por citoquinas ${ }^{1}$.

\section{Virus del papiloma humano}

El virus del papiloma humano (VPH) presenta un amplio espectro de manifestaciones clínicas afectando estructuras cutáneas y mucosas del cuerpo. De acuerdo a los reportes de la literatura médica, la infección por VPH se manifiesta clínicamente en distintas zonas anatómicas, entre las que se incluyen el tracto ano-genital, uretra, piel, laringe, mucosa traqueo-bronquial, cavidad nasal, senos paranasales y cavidad oral ${ }^{15}$.

La infeccion por VPH en la mucosa oral está asociada a distintas entidades clínicas cuyo aspecto puede variar desde lesiones de tipo benigno, con características hiperplásicas, papilomatosas o verrucosas, hasta lesiones de aspecto carcinomatoso ${ }^{16}$. En la literatura médica se ha reportado presencia de VPH en lesiones como papiloma escamoso, verruga vulgar (verruga vulgaris), condiloma acuminado, hiperplasia epitelial focal, leucoplasia pilosa, hiperplasia papilar, liquen plano y carcinoma verrucoso. Aún más, se ha demostrado que el papiloma escamoso, el condiloma acuminado, la verruga vulgar y la hiperplasia epitelial focal están fuertemente vinculados a la presencia de $\mathrm{VPH}^{17}$. El interés en el estudio de estas lesiones, que en los últimos 20 años ha aumentado considerablemente, radica en su potencial rol en la patogénesis de tumores malignos, particularmente del carcinoma escamoso ${ }^{17}$.

Se definen clínicamente las siguientes lesiones como más relevantes dentro de las manifestaciones orales provocadas por el VPH en pacientes con infección por VIH/SIDA:

\section{Papiloma de células escamosas}

Es un tumor relativamente común del epitelio oral, considerada una lesión benigna. Clínicamente, los papilomas orales, como comúnmente se les denomina, se caracterizan por presentar una superficie irregular con proyecciones digitiformes que se asemejan a la superficie de una coliflor ${ }^{17}$ (Figura 9).

\section{Condiloma acuminado}

También se le conoce como verruga venérea y es considerado como una enfermedad de transmisión sexual que afecta la piel y las membranas mucosas del tracto ano-genital. Actualmente se acepta que los condilomas orales pueden aparecer, no solamente por sexo oral, sino que también por auto-inoculacion o como resultado de transmision vertical, de la madre al hijo ${ }^{17}$. Generalmente se presenta como múltiples nodulos pequeños de color blanco o rosado, que proliferan y coalescen. La superficie es más irregular que en los papilomas orales, y son menos frecuentes ${ }^{16}$.

\section{Verruga oral}

Corresponde a la lesión prevalente provocada por VPH en la piel, pero también se encuentra en la mucosa oral. $\mathrm{Su}$ localización más frecuente es en las áreas mucosas donde la queratinización del epitelio se asemeja a la de la piel, como por ejemplo, paladar duro y encía. Debe enfatizarse en que el diagnóstico de verruga oral se reservará para aquellas lesiones que muestran caracteristicas histológicas de la verruga vulgar de la piel ${ }^{17}$.

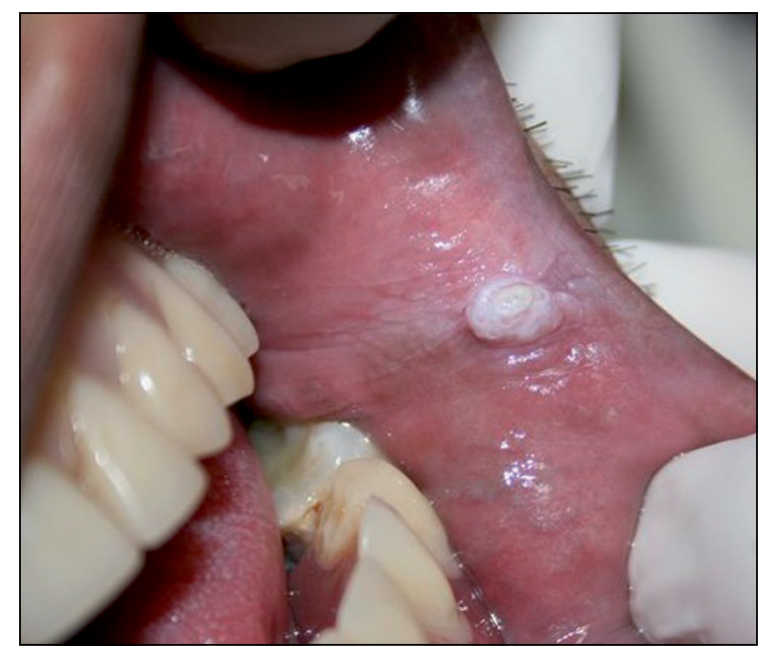

Figura 9. Papiloma escamoso en la cara interna de la mejilla (Hospital San Juan de Dios). 
Clínicamente aparecen como lesiones exofíticas firmes, blanquecinas, de limites definidos, sésiles, que muchas veces muestran queratinización de su superficie ${ }^{16}$.

Las tres entidades descritas comparten muchas caracteristicas clínicas, por lo que al examen, estas lesiones son prácticamente indistinguibles. La biopsia y su posterior estudio histopatológico podrá determinar exclusivamente si se trata de una lesión de tipo papilomatosa o no. En este contexto, el diagnóstico diferencial debe hacerse, por lo general, con hiperplasias irritativas o fibromas irritativos y lipomas que muchas veces, por el trauma masticatorio que subre la mucosa oral, pueden queratinizarse. Para obtener un diagnóstico certero, es ideal tomar una muestra con cepillo citologico de la lesión bucal y someterla a genotipificación en base a técnicas de RPC y microarreglo (en inglés microarray).

\section{Úlceras inespecíficas (úlceras orales recurrentes)}

Las úlceras orales recurrentes inespecíficas asociadas a la infección por VIH suelen ser generalmente mayores de $0,5 \mathrm{~cm}$, pudiendo alcanzar diámetros de $2-3 \mathrm{~cm}$ en algunos pacientes $^{1}$. Se pueden localizar en mucosa epitelial no queratinizada pero también en mucosa queratinizada y oro-faringe, en pacientes con mayor inmunosupresión. Pueden persistir durante mucho tiempo, a veces incluso semanas o meses, dejando una cicatriz ${ }^{1}$ (Figura 10).

Pueden presentarse como lesiones únicas o múltiples y son extremadamente dolorosas. Están bien delimitadas, aunque es común que a estas úlceras les falte el característico halo eritematoso, debido a la inmunosupresión que padecen los pacientes. Son consideradas idiopáticas por lo que su diagnóstico se hace al excluir otras lesiones que cursan con úlceras de origen conocido. Hay que poner

Figura 10. Gran úlcera en la punta y dorso lingual (Hospital San Juan de Dios). especial énfasis en la historia y en los signos clínicos ya que entidades infecciosas o condiciones neoplásicas también pueden cursar con úlceras en algunas etapas de su etio-patogenia, como por ejemplo, infecciones por citomegalovirus, estadios iniciales del carcinoma escamoso, infecciones fúngicas o bacterianas y virus herpes simplex.

Si bien tienen una resolución espontánea, es recomendable indicar a los pacientes que disminuyan la ingesta de alimentos ácidos o con gran cantidad de aliños ya que por presentar una superficie cruenta, el contacto con estos alimentos resulta bastante doloroso. Cuando son de un tamaño pequeño, tienden a remitir dentro de los 7-14 días; sin embargo, cuando son de gran tamaño pueden perdurar por varias semanas.

\section{Patologías de glándulas salivales}

\section{Hiperplasia de las glándulas salivales}

Puede ser, en algunos pacientes, la primera manifestación clínica de la infección por VIH. La patogenia de este proceso inflamatorio no está aclarada en su totalidad, e incluso, algunos autores sostienen que puede deberse no sólo al VIH, sino a otros virus que en situación de inmunodeficiencia pueden aislarse en tejidos glandulares salivales, como algunos tipos de herpesvirus humano, adenovirus y citomegalovirus ${ }^{1}$. Afecta con mayor frecuencia a la glándula parótida que a la submandibular y causa muchas veces una importante deformidad facial.

Pero no solamente la causa de esta hiperplasia es infecciosa, también puede ser producto de lesiones linfo-epiteliales, quistes, linfomas, lesiones tumorales y linfocitosis por síndrome de infiltración difusa (DILS por su nombre en inglés), donde existe una linfocitosis producida por aumento de linfocitos T CD8 circulantes $^{1}$.

En relación al diagnóstico, debe estudiarse como primera instancia, la naturaleza del aumento de volumen, evaluando si la es de origen tumoral, neoplásico o quístico, lo cual puede realizarse a través de una ecografía y dependiendo de estos hallazgos, solicitar una TAC o RM.

\section{Hiposialia e hipofunción glandular}

Puede provocarse como resultado de la infección por VIH, efecto colateral de TARV, patologías de glándulas salivales mayores e incluso por el uso de fármacos antidepresivos que estos pacientes utilizan como coadyuvantes del tratamiento.

\section{Virus herpes simplex}

La infección por VHS es generalizada en la población mundial y sus lesiones orales son bastante comunes: vesículas seguidas de un pródromo que cursa con sensación urente y posteriormente la formación de una úlcera que remite dentro de 10-14 días. No se considera como un 
indicador diagnóstico de infección por VIH útil ya que no se relaciona con el recuento de linfocitos T CD4 o la carga viral de forma significativa. Sin embargo, en pacientes con infección por VIH la persistencia de lesiones puede ser prolongada e incluso presentarse en lugares que no son habituales como en sitios con mucosa no queratinizada ${ }^{1,9}$.

Son virus con características neurotrópicas que pueden permanecer en estado de latencia hasta que por ciertos estímulos o por inmunosupresión pueden dar manifestaciones clínicas. Por lo general, las lesiones involucran labios, ya sea a nivel del bermellón o en la piel de la región adyacente o cavidad oral como encía, paladar y dorso lingual.

El diagnóstico del herpes labial o intra-oral se basa en la anamnesis y en los signos clínicos encontrados, aunque también puede realizarse diagnóstico a través de exámenes de biología molecular como RPC.

\section{Conclusión}

El conocimiento de las distintas presentaciones clínicas, síntomas y comportamiento de las lesiones orales es fundamental para realizar un diagnóstico y tratamiento oportuno en pacientes con infección por VIH/SIDA, así como también realizar una sospecha diagnóstica en caso de desconocimiento de la enfermedad inmunosupresora de base y además monitorizar el éxito o fracaso de TARV.

Sin embargo, considera esta autora que lo más importante de conocer las características clínicas de las distintas manifestaciones orales asociadas a la infección por VIH/ SIDA tiene que ver con la unificación de criterios diagnósticos que nos permitan conocer la frecuencia de estas lesiones en la población VIH/SIDA. Ello contribuiría en la elaboración de políticas de salud pública, con un fuerte sustento epidemiológico, y en robustecer las estadísticas en salud que en nuestro país son prácticamente inexistentes en el ámbito de la cirugía buco máxilo-facial.

\section{Resumen}

Dentro de las manifestaciones que pueden aparecer en los pacientes con infección por VIH/SIDA, las lesiones de la cavidad oral tienen gran relevancia debido a que son fácilmente accesibles y por lo general su diagnóstico se efectúa a través de signos clínicos. Además, algunas manifestaciones orales están fuertemente relacionadas con el síndrome por lo que indican sospecha de infección y progresión a etapa SIDA y permiten monitorizar el éxito o fracaso de la terapia anti-retroviral empleada. La introducción masiva de la terapia anti-retroviral ha modificado la morbi-mortalidad, la frecuencia, el tipo de manifestación clínica y el momento de aparición de las clásicas complicaciones oportunistas. El objetivo de esta revisión es entregar las características clínicas clásicas actualizadas de aquellas manifestaciones orales asociadas a la infección por VIH/SIDA que son más frecuentes y que tienen mayor relevancia clínica, considerando las características fundamentales para su diagnóstico.

\section{Referencias bibliográficas}

1.- Patton L. Oral lesions associated with human immunodeficiency virus disease. Dent Clin North Am 2013; 57: 673-98.

2.- Coogan M M, Greenspan J, Challacombe S J. Oral lesions in infection with human immunodeficiency virus. Bull World Health Org 2005; 83: 700-6.

3.- Wilson G, Wolff M. Una década de terapia anti-retroviral: Perfil de pacientes con 10 años de triterapia de alta efectividad. Rev Chilena Infectol 2012; 29 (3): 337-43.

4.- Patton L L, Ramírez-Amador V, Anaya-Saavedra G, Nittayananta W, Carrozzo M, Ranganathan K. Urban legends series: oral manifestations of HIV infection. Oral Diseases 2013; 19: 533-50.

5.- Patton L L, Phelan J A, Ramos-Gómez F J, Nittayananta W, Shiboski C H, Mbuguye T L. Prevalence and classification of HIV-associated oral lesions. Oral Diseases 2002; 8: 98-109.

6.- Greenspan J S, Greenspan D. The epidemiology of the oral lesions of HIV infection in the developed world. Oral Diseases 2002; 8: 34-9.

7.- McLean A T, Wheeler E K, Cameron S, Baker D. HIV and dentistry in Australia: clinical and legal issuesimpacting on dental care. Australian Dental J 2012; 57: 256-70.

8.- EEC Clearinghouse on oral problems related to HIV infection and WHO Collaborating Center on oral manifestations of the human immunodeficiency virus. Classification and diagnostic criteria for oral lesions in HIV infection. J Oral Pathol Med 1993; 22: 289-91.

9.- Shiboski C H, Patton L, Webster-Cyriaque J Y, Greenspan D, Traboulsi R, Ghannoum M, et al. The Oral HIV/AIDS Research Alliance: updated case definitions of oral disease endpoints. J Oral Pathol Med 2009; 38: 481-8.

10.- Donoso F. Capítulo 20: Manifestaciones orales en pacientes VIH/SIDA. Sepúlveda C, Afani A. SIDA. Cuarta Edición. Santiago. Editorial Mediterráneo 2009; p 162-73.

11.- Reznik D A. Oral manifestations of HIV disease. Top HIV 2005 Med; 13 (5): 143-8.
12.- Aguirre J M, Echebarría M A, Eguía A. Síndrome de inmunodeficiencia adquirida: manifestaciones en la cavidad bucal. Med Oral Patol Oral Cir Bucal 2004; 9: 148-57.

13.- Fatahzadeh M. Kaposi sarcoma: review and medical management update. Oral Surg Oral Med Oral Pathol Oral Radiol 2012; 113 : 2-16.

14.- Ryder M, Nittayananta W, Coogan M, Greenspan D, Greenspan J. Periodontal disease in HIV/AIDS. Periodontol 2000. 2012; 60: 78-97.

15.- Campisi G, Panzarella V, Giuliani M, Lajolo C, Fede O, Falaschini S, et al Human papillomavirus: Its identikit and controversial role in oral oncogenic, premalignant and malignant lesions (Review). Int J Oncol 2007; 30: 813-23.

16.- Kumaraswamy K L, Vidhya M. Human papilloma virus and oral infections: An update. J Cancer Res Ther 2011; 7 (2): 120-7.

17.- Syrjänen S. Human papilloma virus infections and oral tumors. Med Microbiol Immunol 2003; 192: $123-8$. 